\title{
EL ACCESO A LA EDUCACIÓN INTEGRAL EN SEXUALIDAD COMO LÍMITE LEGÍTIMO AL DERECHO DE LOS PADRES A ELEGIR LA EDUCACIÓN PARA SUS HIJOS
}

Access to Comprehensive Sexuality Education as a legitimate limit to the right of parents to choose education for their children

\section{Francisco Javier Urizar Pérez}

Licenciado en Ciencias Jurídicas y Sociales, Abogado y Notario, Universidad Rafael Landívar

Magister en bioética, Universidad del Istmo

Magister en Derecho Constitucional, Universidad Rafael Landívar

Magister en Derechos Humanos y Democratización, Universidad Nacional de San Martín

Doctorando en Derecho Constitucional Internacional,

Universidad de San Carlos de Guatemala

ORCID Id. https://orcid.org/0000-0003-1114-8417

fjurizargt@gmail.com https://doi.org/10.37346/opusmagna.v16i01.14

Fecha de recepción: 30/09/2019

Fecha de aceptación: 20/02/2020 


\section{SUMARIO}

\section{Introducción}

1. ¿Qué se entiende por educación integral en sexualidad?

2. El derecho de los padres a elegir la educación que desean para sus hijos

3. La libertad de religión

\section{Conclusión \\ Bibliografía}

Resumen
Existe una tensión constante entre varios
sectores en torno al reconocimiento
del acceso a la educación integral en
sexualidad como un derecho humano
autónomo para los niños, niñas
y adolescentes dentro del sistema
educativo nacional. Los argumentos más
utilizados por la oposición devienen de
planteamientos relativos a la potestad de
los padres de decidir el tipo de educación
que quieren para sus hijos menores de
edad. El tema ha llegado al conocimiento
de la Corte de Constitucionalidad que ha
tenido que ponderar entrela prerrogativa
de los padres y la educación de los niños,
niñas y adolescentes, desarrollando los
límites y los contenidos esenciales de los
derechos que asisten a cada grupo en el
marco de una sociedad democrática.
Palabras clave: Derechos humanos,
Educación integral en sexualidad,
límites a los derechos humanos, juicio de
ponderación.

Abstract
There is a constant tension between
various sectors around the recognition
of access to comprehensive sexuality
education as an autonomous human
right for children and adolescents
within the national education system.
The arguments most commonly used
by the opposition are in the footsteps
of parental authority to decide the
type of education they want for their
underage children. The issue has come
to the attention of the Constitutional
Court that has had to weigh between
the prerogative of parents and the
education of children and adolescents,
developing the limits and essential
content of the rights that assist each
group within the framework of a
democratic society.
Keywords: Human rights,
comprehensive education in sexuality,
limits on human rights, weighting
judgment.




\section{INTRODUCCIÓN}

La sexualidad es una de las dimensiones de la personalidad que se manifiesta en todas los ámbitos de la vida. Su contenido está definido por una amplia gama de factores que están directamente relacionados con el desarrollo de las sociedades. A raíz de la demarcación del contenido del derecho a la educación se ha desarrollado el derecho a la educación en derechos humanos, dentro de la que se enmarca la educación en sexualidad. Atendiendo al derecho que asiste a los niños, niñas y adolescentes a recibir una educación integral que les permita desarrollar su personalidad y un plan de vida que favorezca alcanzar una vida digna en una sociedad democrática y plural, se plantea la necesidad de brindar una educación integral.

A través de una investigación documental, en la que se analizaron fuentes bibliográficas, normativas y jurisprudenciales, se pretende establecer los criterios que han sido tomados en cuenta por la Corte de Constitucionalidad para delimitar los límites y los alcances del derecho de los niños, niñas y adolescentes a recibir una educación integral en sexualidad y el de los padres a decidir el tipo de educación que desean para sus hijos. Si bien, el derecho a la educación es de carácter universal y se aplica también a adultos, el objeto de estudio del presente trabajo es el que se refiere exclusivamente a quienes se tienen una edad menor a los 18 años.

El trabajo se divide en cuatro partes. En la primera se analiza lo referente a la sexualidad humana y su vinculación con el derecho a la educación. En la segunda, se presentan algunos criterios relativos al derecho de los padres a elegir la educación para sus hijos; en la tercera, se aborda brevemente el derecho a la libertad religiosa y sus límites y, finalmente, un apartado de conclusiones.

A través de la investigación realizada se logra confirmar la pregunta de la investigación, concluyendo que, en efecto, el derecho a acceder a una educación integral en sexualidad es un límite legítimo para el derecho de los padres a elegir la educación que desean para sus hijos. 


\section{1. ¿Qué se entiende por educación integral en sexualidad?}

\subsection{El concepto de sexualidad.}

Hablar de sexualidad supone el análisis de una serie de consideraciones de tipo filosófico, político, religioso, legal, médico, psicológico, antropológico y de otras ciencias porque la sexualidad es "un fenómeno pluridimensional que varía de una cultura a otra y en el contexto socio-histórico en que se desarrolle" (Vera-Gamboa, 1998, pág. 118). Es importante tener en cuenta que, al hacer referencia a este término, no se está hablando de un dato o un hecho, sino de un fenómeno que es construido socialmente (Córdoba García, 2007). Para hablar de sexualidad es pertinente partir de algunos supuestos:

a. La sexualidad es un aspecto fundamental de la vida humana, con dimensiones físicas, sicológicas, espirituales, sociales, económicas, políticas y culturales.

b. No es posible entender la sexualidad sin referencia al género.

c. La diversidad es una característica fundamental de la sexualidad.

d. Las normas que rigen el comportamiento sexual varían drásticamente entre y dentro de las culturas. Ciertos comportamientos se consideran aceptables y deseables mientras que otros se consideran inaceptables. Esto no significa que los comportamientos no ocurran o que deberían ser excluidos del debate en el contexto de la educación en sexualidad (Unesco, 2010, pág. 2).

Teniendo esto presente, es posible afirmar que, a lo largo de la historia, en las diferentes épocas y lugares, han existido varios tipos de procesos de formación u orientación que, desde lo público y lo privado, han marcado las pautas de desarrollo, comportamiento, roles, derechos y obligaciones de las personas en torno a la vivencia y manifestación de la sexualidad propia y ajena. Estos procesos han evolucionado junto con las sociedades, lo que ha provocado que varias de las normas que regían aspectos de la sexualidad hayan sido superadas y desaplicadas con el paso del tiempo; un ejemplo de esto es la norma sobre la violación contenida en el libro del Deuteronomio: 
Si una mujer virgen está prometida a un hombre y otro hombre la encuentra en la ciudad y se acuesta con ella, los sacaréis a los dos a la puerta de esa ciudad y los apedrearéis hasta que mueran: a la joven por no haber pedido socorro en la ciudad, y al hombre por haber violado a la mujer de su prójimo. Así harás desaparecer el mal en medio de ti. Pero si es en el campo donde el hombre encuentra a la joven prometida, la fuerza y se acuesta con ella, sólo morirá el hombre que se acostó con ella; no harás nada a la joven: no hay pecado que merezca la muerte. El caso es semejante al de un hombre que se lanza sobre su prójimo y le mata: porque fue en el campo donde la encontró, y la joven prometida acaso gritó sin que hubiera nadie que la socorriera (Deuteronomio 22, 23-27).

En Guatemala, actualmente, se entiende que la indemnidad sexual es un bien jurídico tutelado y la integridad personal es un derecho de la persona, en consecuencia, la violación es un delito que debe ser perseguido por el Ministerio Público para poder enjuiciar y sancionar a los responsables de acuerdo con la legislación aplicable. A pesar del fuerte influjo que tiene la tradición judeocristiana en la cultura guatemalteca, el Estado no puede asumir como un principio rector de su política criminal los preceptos deuteronómicos.

En este tiempo es impensable castigar con la muerte a una mujer víctima de una violación o de considerar el delito en función del prometido y no de la persona que lo sufrió. Así, es más fácil entender que, al igual que en otras materias, en lo que respecta a la sexualidad el paso del tiempo, las experiencias de la humanidad, la evolución de las sociedades y el desarrollo de los derechos humanos, permiten una comprensión más amplia y humanizada de su contenido.

Pero no es necesario remontarse a los textos bíblicos o a épocas remotas para entender la evolución que ha tenido la comprensión de algunos aspectos de la sexualidad en una sociedad concreta. Una de las formas en las que se ponen en evidencia con mayor contundencia los estereotipos sobre los roles de género en una sociedad es la forma en la que se encuentran regulados los derechos y obligaciones de los hombres y las mujeres unidos en matrimonio. 
En Guatemala, el Código Civil entró en vigor en el año 1963 y en sus normas está contenido el peso de la ideología predominante respecto a los roles de los hombres y las mujeres en la sociedad, los derechos y obligaciones que nacen del matrimonio están recogidos en los artículos 108 al 114 del citado cuerpo legal. El 24 de junio de 1993 la Corte de Constitucionalidad resolvió sobre la inconstitucionalidad directa planteada por la Procuradora Adjunta de los Derechos Humanos en contra de varios artículos del Código Civil, que permitían y perpetuaban condiciones de desigualdad, colocando a la mujer en una situación de sometimiento frente al hombre dentro del matrimonio.

En esa oportunidad, la Corte de Constitucionalidad planteó como una premisa general que tendría presente para las consideraciones del caso la siguiente:

Cuando la persona se integra a la institución del matrimonio, la autonomía de la voluntad opera como elemento esencial en su máxima expresión de libertad y, siendo el legislador quien crea las normas, lo hace en protección de valores superiores en favor de la familia, los menores, la paternidad y la maternidad responsable. En el matrimonio hay un papel para cada uno de los cónyuges, el que determina el Estado dentro de los valores tradicionales guatemaltecos y la diversidad de concepciones, costumbres y creencias nacionales en relación con el matrimonio. El Estado ha regulado la institución con normas precisas para que den certeza y seguridad jurídica a cada uno de los cónyuges (Corte de Constitucionalidad, 1993, pág. 6).

En lo relativo a la norma que se vinculaba con la limitación al derecho al trabajo para las mujeres, la Corte consideró, entre otras cosas lo siguiente:

En todo caso, corresponde a cada esposa atender sus actividades de trabajo y cumplir con las responsabilidades de madre que le impone el matrimonio. Eliminar la obligación de velar por la atención y cuidado de los hijos constituiría un acto contrario a los derechos del niño y del adolescente que garantiza el artículo 51 de la Constitución (pág. 10). 
La consecuencia de esta resolución fue la presentación de una petición ante la Comisión Interamericana de Derechos Humanos, denunciando las condiciones de discriminación que generaba la vigencia de esas normas del Código Civil. La Comisión emitió el informe de admisibilidad sobre ese caso y dentro de sus valoraciones consideró:

En el caso que nos ocupa, María Eugenia Morales de Sierra alega que las disposiciones del Código Civil impugnadas establecen distinciones por motivos de género, que infringen sus derechos a la igualdad ante la ley y a igual protección de la ley, simplemente por virtud de su vigencia. A este respecto, la jurisprudencia internacional ha establecido que una ley puede violar el derecho de un individuo inclusive en ausencia de una medida específica de aplicación posterior dispuesta por las autoridades, en los casos en que las personas se ven directamente afectadas o corren riesgo inminente de ser afectadas directamente por una disposición legislativa [... María Eugenia Morales de Sierra "impugna una situación legal" --la de una mujer casada comprendida en los citados artículos del Código Civil-- "que la afecta personalmente" [...] La Comisión considera que el efecto directo de las disposiciones legislativas impugnadas en los derechos y la vida cotidiana de la víctima ha sido alegado y demostrado adecuadamente para los propósitos de admisibilidad del presente caso (Comisión Interamericana de Derechos Humanos, 1998, párr. 35).

Respecto al trato diferenciado que generaban los artículos del Código Civil impugnados, la Comisión estableció:

Los artículos 109, 110, 113, 114, 115, 131, 133, 255 y 317 del Código Civil establecen diferencias en el tratamiento que prescribe la ley con respecto a las mujeres casadas y a los hombres casados, y en algunos casos, a las mujeres casadas y a las mujeres solteras. En el marco de la legislación internacional sobre derechos humanos, deben analizarse esas diferencias para determinar si procuran un objetivo legítimo, y si los medios empleados son proporcionales al fin que se busca [...] En otras palabras, se espera un tratamiento equitativo de la ley para hombres y mujeres, a menos que se hayan aducido motivos justos, legítimos y razonables imperiosos para justificar una diferencia de tratamiento (párr. 36). 
Finalmente, el 23 de diciembre de 1998 fue publicado en el Diario Oficial el Decreto 80-98 del Congreso de la República de Guatemala, que contiene "Reformas al decreto ley 106 del Jefe de Gobierno, Código Civil" en el que se derogaron o modificaron varias de las normas que fueron impugnadas ante la Corte de Constitucionalidad y posteriormente denunciadas ante el Sistema Interamericano de Derechos Humanos.

En su parte considerativa el decreto referido expresa que algunas normas del Código Civil no son compatibles plenamente con la Constitución Política de la República, con principios reconocidos internacionalmente en materia de Derechos Humanos, ni con "las tendencias modernas del Derecho", además, que la supresión de las disposiciones legales que conlleven perjuicio en contra de las mujeres, es una obligación derivada de la ratificación de la Convención para la Eliminación de todas las formas de Discriminación contra la Mujer. Finalmente, resalta la obligación de los Estados parte de los instrumentos internacionales sobre Derechos Humanos de garantizar a hombres y mujeres, la igualdad en el goce de todos los derechos.

En la parte sustantiva del decreto se reforma el artículo 109 del Código Civil, estableciendo que la representación conyugal corresponde a ambos cónyuges y que estos tendrán autoridad y consideraciones iguales en el hogar. Se reformó el segundo párrafo del artículo 110 para que ambos cónyuges tengan la obligación de cuidar y atender a sus hijos. Finalmente, se derogó el artículo 114.

En este caso, se ve reflejado un cambio radical en la forma de entender las relaciones entre hombres y mujeres vinculados por el matrimonio, generando una nueva situación jurídica para las mujeres casadas por el reconocimiento del desarrollo progresivo del contenido del derecho a la igualdad ante la ley contenido en la Constitución y los instrumentos internacionales en materia de derechos humanos. Las formas de ejercicio del poder en las relaciones entre hombres y mujeres forman parte del contenido de los roles asignados a cada género en el contexto que ofrece una sociedad, esto supone una vinculación de actividades de cierto tipo a quienes representan lo masculino y otro tipo de actividades a quienes representan lo femenino, evidentemente esto no tiene que ver con los órganos genitales que tenga la persona o con la procreación, sin 
embargo, sí está marcado por una diferenciación de tipo social y política que es abarcada por la sexualidad.

En consecuencia, puede colegirse que la sexualidad abarca un campo mucho más amplio que lo relacionado con sexo, si bien, tiene como punto de partida la realidad sexual, su contenido considera a la persona como un ser completo. Se relaciona más con la forma en la que pone de manifiesto en una sociedad el sexo de la persona y se reconoce que esta manifestación está influenciada por múltiples variables como la histórica, cultural, psicológica, religiosa, legal, etcétera.

Para finalizar este apartado, vale la pena traer a colación la definición de sexualidad que proporcionan la Organización Mundial de la Salud y la Organización Panamericana de la Salud, citada por Arango de Montis (2008):

El término 'sexualidad' se refiere a una dimensión fundamental del hecho de ser un humano: basada en el sexo, incluye al género, las identidades de sexo y género, la orientación sexual, el erotismo, la vinculación afectiva y el amor, y la reproducción. Se experimenta o expresa en forma de pensamientos, fantasías, deseos, creencias, actitudes, valores, actividades, prácticas, roles y relaciones. La sexualidad es el resultado de la interacción de factores biológicos, psicológicos, socioeconómicos, culturales, éticos y religiosos o espirituales (pág. 5).

Es importante tener claro que, aunque la sexualidad está influida por todos estos factores, no es indispensable que se experimenten o expresen todos, aunque, para ambos organismos internacionales, "la sexualidad se expresa en todo lo que somos, sentimos, pensamos y hacemos".

\subsection{La sexualidad y la educación.}

Habiendo abordado el concepto de sexualidad y sus posibles definiciones es prudente iniciar la discusión de uno de los temas centrales de este trabajo: la educación integral en sexualidad. Al comprender la multidimensionalidad de la sexualidad humana, resulta evidente que una educación integral en ese aspecto de la personalidad no puede referirse únicamente a lo relativo a lo biológico- 
fisiológico, sino que debe tener en cuenta las distintas facetas de influencia y de manifestación que tiene esta. No se puede hablar de integralidad en un proceso de formación, si en los alcances de este se pretende agotar un problema analizando solamente una de sus aristas.

En sí mismo, el derecho a la educación tiene una serie de características que lo dotan de alcances particulares para la vida de las personas, el desarrollo económico y democrático de los pueblos y la construcción y mantenimiento de la paz entre las naciones. De esa cuenta, se considera como parte de él el acceso a una educación para los derechos humanos, lo que se desprende de los artículos de la Declaración Universal de los Derechos Humanos y otros instrumentos internacionales. De acuerdo con la Unesco:

La idea que sustenta la educación en la esfera de los derechos humanos es que la educación no debería aspirar únicamente a formar a trabajadores capacitados y profesionales, sino también a contribuir al desarrollo de personas con capacidad para interrelacionarse y actuar en una sociedad justa. Mediante la educación para los derechos humanos, o los derechos humanos en la educación, se pretende dotar a los alumnos y estudiantes de las aptitudes necesarias para adaptarse a los cambios sociales e impulsarlos (Unesco, 2003, pág. 1).

Una educación enfocada en derechos humanos trasciende de la simple repetición o réplica de contenidos teóricos; abarca los procesos y experiencias de aprendizaje que puedan aportar al desarrollo pleno de la personalidad dentro de una sociedad, porque su objetivo es favorecer que las personas puedan participar en su comunidad de forma constructiva y respetuosa respecto a sí mismas y a los demás.

La Asamblea General de la Organización de las Naciones Unidas aprobó la Declaración de las Naciones Unidas sobre educación y formación en derechos humanos, mediante la cual reafirma el derecho a la educación reconocido a todas las personas el cual debe orientarse hacia el pleno desarrollo de la personalidad humana y del sentido de su dignidad, con la intención de capacitarlas para participar efectivamente en una sociedad libre; así como el deber de los Estados de encauzar la educación de manera que se fortalezca el 
respeto a los derechos humanos y las libertades fundamentales contenidos en los instrumentos del Sistema de Naciones Unidas. De acuerdo con el artículo 1 de esta declaración:

Toda persona tiene derecho a poseer, buscar y recibir información sobre todos los derechos humanos y las libertades fundamentales y debe tener acceso a la educación y la formación en materia de derechos humanos (Asamblea General, 2012).

Como se ha visto, la sexualidad es una parte de la personalidad humana que está influida por diferentes aspectos de la vida personal y social de las personas y que se manifiesta en todos los aspectos de la vida, de esa cuenta, se puede entender que existe una vinculación directa entre la vivencia y la manifestación de la sexualidad y los derechos humanos. Las formas en las que se construye y se experimenta la sexualidad de una persona están determinadas por intervenciones de diversa naturaleza que al analizarse a la luz de los estándares internacionales en materia de derechos humanos pueden redundar en su respeto o violación.

En la Constitución Política de la República de Guatemala, el derecho a la educación se reconoce en el artículo 71 como una obligación del Estado, que debe proporcionarla y facilitarla a todos los habitantes de la República sin discriminación. Por su parte, el artículo 72 desarrolla los fines de la educación y establece como tales el desarrollo integral de la persona, el conocimiento de la realidad y cultura nacional y universal; asimismo, declara de interés nacional la enseñanza sistemática de la Constitución de la República y de los derechos humanos. Así, la ley fundamental guatemalteca se encuentra en consonancia con los instrumentos internacionales de derechos humanos en lo relativo al contenido de este derecho. ${ }^{1}$

1 Declaración Universal de los Derechos Humanos. Artículo 26. 1. Toda persona tiene derecho a la educación. La educación debe ser gratuita, al menos en lo concerniente a la instrucción elemental y fundamental [...]

2. La educación tendrá por objeto el pleno desarrollo de la personalidad humana y el fortalecimiento del respeto a los derechos humanos y a las libertades fundamentales; favorecerá la comprensión, la tolerancia y la amistad entre todas las naciones y todos los grupos étnicos o religiosos; y promoverá el desarrollo de las actividades de las Naciones Unidas para el mantenimiento de la paz. 
De acuerdo con estos estándares, el proceso educativo al que tienen derecho todas las personas está enfocado a propiciar que alcancen su máximo potencial, desarrollando su libertad moral para construir su propio proyecto de vida, el cual, debe estar orientado a su cumplimiento dentro de una sociedad plural y respetuosa de los derechos humanos y las libertades fundamentales de todos sus habitantes.

Aportar al desarrollo integral de la persona ${ }^{2}$ a través de la educación supone cotar con un sistema educativo en el que se reconozca la "primacía de la persona humana como sujeto y fin del orden social" tal y como lo afirmaron

\begin{abstract}
Pacto Internacional de Derechos Económicos, Sociales y Culturales. Artículo 13.1. Los Estados partes en el presente Pacto reconocen el derecho de toda persona a la educación. Convienen en que la educación debe orientarse hacia el pleno desarrollo de la personalidad humana y del sentido de su dignidad, y debe fortalecer el respeto por los derechos humanos y las libertades fundamentales. Convienen asimismo en que la educación debe capacitar a todas las personas para participar efectivamente en una sociedad libre, favorecer la comprensión, la tolerancia y la amistad entre todas las naciones y entre todos los grupos raciales, étnicos o religiosos y promover las actividades de las Naciones Unidas en pro del mantenimiento de la paz.
\end{abstract}

Convención sobre los Derechos del Niño. Artículo 28. 1. Los Estados Partes reconocen el derecho del niño a la educación y, a fin de que se pueda ejercer progresivamente y en condiciones de igualdad de oportunidades [...]

Artículo 29. 1. Los Estados Partes convienen en que la educación del niño deberá estar encaminada a: a) Desarrollar la personalidad, las aptitudes y la capacidad mental y física del niño hasta el máximo de sus posibilidades; b) Inculcar al niño el respeto de los derechos humanos y las libertades fundamentales y de los principios consagrados en la Carta de las Naciones Unidas; c) Inculcar al niño el respeto de sus padres, de su propia identidad cultural, de su idioma y sus valores, de los valores nacionales del país en que vive, del país de que sea originario y de las civilizaciones distintas de la suya; d) Preparar al niño para asumir una vida responsable en una sociedad libre, con espíritu de comprensión, paz, tolerancia, igualdad de los sexos y amistad entre todos los pueblos, grupos étnicos, nacionales y religiosos y personas de origen indígena; e) Inculcar al niño el respeto del medio ambiente natural.

Protocolo de San Salvador. Artículo 13.1. Toda persona tiene derecho a la educación.

2. Los Estados partes en el presente Protocolo convienen en que la educación deberá orientarse hacia el pleno desarrollo de la personalidad humana y del sentido de su dignidad y deberá fortalecer el respeto por los derechos humanos, el pluralismo ideológico, las libertades fundamentales, la justicia y la paz. Convienen, asimismo, en que la educación debe capacitar a todas las personas para participar efectivamente en una sociedad democrática y pluralista, lograr la subsistencia digna, favorecer la comprensión, la tolerancia y la amistad entre todas las naciones y todos los grupos raciales, étnicos o religiosos y promover las actividades en favor del mantenimiento de la paz.

2 De acuerdo con el artículo $2^{\circ}$ de la Constitución guatemalteca "Es deber del Estado garantizarles a los habitantes de la República [...] el desarrollo integral de la persona”. 
los constituyentes en el preámbulo de la ley fundamental guatemalteca y, atendiendo esto, entender a la persona en su complejidad, con todos los aspectos que integran su ser; $y$, partiendo de ese reconocimiento, plantear programas de formación que aporten, desde el enfoque más integral posible, al autodescubrimiento de los individuos y su proyección para participar de forma democrática en una sociedad diversa y cambiante.

Comprender la multidimensionalidad de los factores que definen y las formas en que se manifiesta la sexualidad humana implica el reconocimiento de su lugar dentro de la integralidad de la persona y la necesidad de su estudio y tratamiento de forma respetuosa y hospitalaria dentro de los procesos educativos formales e informales que ofrece el sistema educativo nacional en todos los niveles, tomando en cuenta que es uno de los aspectos de la personalidad que más influye en la vida de las personas y que se encuentra en mayor riesgo de ser vulnerado desde las primeras etapas de la vida.

\subsection{La educación integral en sexualidad como parte de la educación en derechos humanos.}

Como parte integrante del derecho general a la educación se encuentra el específico a la educación en derechos humanos que, de acuerdo con la Declaración citada anteriormente, comprende el derecho a "poseer, buscar y recibir información" relativa a estos. En el apartado anterior se propuso un concepto de sexualidad que comprende una diversidad de factores que la integran y de formas y ambientes en los que se manifiesta, sin el ánimo de agotar el tema, esta conceptualización puede servir para justificar la relación entre la sexualidad y el derecho a la identidad, al trabajo, la libertad personal y de acción, la integridad física y mental, la igualdad ante la ley, a vivir libre de violencia, todos ellos vinculados de forma directa con aquella.

En este marco pueden entenderse las palabras del relator especial de las Naciones Unidas sobre el derecho a la educación (2010) cuando afirmó: "el derecho a la educación sexual integral hace parte del derecho de las personas a ser educadas en derechos humanos" (pág. 7). De acuerdo con el relator, una educación integral en materia de sexualidad puede colaborar con la persona para explorar sus propios valores y actitudes y con ello favorecer la toma de 
decisiones y habilidades de comunicación. Si se leen con detenimiento, estas declaraciones presentan una visión de la educación integral en sexualidad que empalma adecuadamente con los fines de la educación en general y la educación en derechos humanos en particular, toda vez que el desarrollo de habilidades para tomar decisiones y comunicarse adecuadamente de acuerdo con los valores propios, representan elementos fundamentales para desenvolverse en una sociedad de forma activa.

Teniendo presente que el ejercicio de la sexualidad es un derecho humano autónomo y el respeto a la sexualidad ajena es una obligación que pesa sobre toda persona, que la sexualidad se vincula con el reconocimiento y ejercicio de otros derechos fundamentales reconocidos en la Constitución y los instrumentos internacionales, es posible reconocer que existe una relación contenido-continente entre la educación integral en sexualidad y la educación en derechos humanos.

\subsection{La educación integral en sexualidad.}

La educación relativa a la sexualidad evoluciona constantemente y es asumida por las sociedades de distinta manera dependiendo de los momentos en los que se encuentran. Es importante tener presente que una de las esperanzas que se tienen sobre los niños, niñas y adolescentes es la reproducción de la sociedad en la que viven, de esa cuenta, se construyen los programas de formación con la finalidad de constituirlos como "buenos ciudadanos" de la sociedad que los educa. Esta realidad repercute en los modelos educativos y en los contenidos de las materias que se imparten.

Analizando las características de los programas de educación de la sexualidad, Unesco (2014) identifica cuatro categorías, según el tipo de abordaje que se quiera utilizar:

a. El modelo moralista. Resultado de la reacción de instituciones conservadoras a otras formas de hacer educación sexual. La sexualidad es lícita únicamente dentro del matrimonio heterosexual y con fines reproductivos. "Sus principales objetivos son fomentar la 
abstinencia como único método seguro y fortalecer el carácter y la voluntad para no sucumbir al sexo antes del matrimonio" (pág. 45).

b. El modelo de riesgo o del "buen comportamiento". Contempla la salud únicamente como la ausencia de enfermedades, de tal cuenta que la sexualidad únicamente merece atención cuando surge algún riesgo o problema. "Su objetivo es prevenir problemas de salud derivados de la actividad sexual y las consecuencias personales, sociales y económicas que provocan" (pág. 46).

c. El modelo integrador o "comprensivo/integral". Entiende la salud en general y la salud sexual en particular como elementos indispensables para la promoción del bienestar y la calidad de vida de todas las personas. Su marco de referencia es el de derechos humanos, sexuales, de la mujer, de la infancia y de las diferentes normas internacionales.

d. El modelo de desarrollo o de "desarrollo y bienestar". Es la evolución del modelo integrador. Abarca la sexualidad en varios componentes y no solo como un tema de salud: identidad, relaciones, expresión, etcétera. "Visualiza la sexualidad como un elemento esencial del desarrollo personal, pero también como un componente clave para el ejercicio de una ciudadanía plena y el logro de su máximo potencial como individuo" (pág. 46).

La propuesta de una educación integral en sexualidad se plantea desde el modelo de desarrollo, el cual, no supone una negación de los contenidos de los demás modelos, sino que los contextualiza y los presenta desde una fórmula de respeto a la libertad y a la capacidad de discernimiento que posea la persona en un determinado momento de su vida.

En el marco de la inclusión de la educación integral en sexualidad como formante de la educación en derechos humanos, Unesco propone una definición de esta, afirmando que consiste en:

Un enfoque culturalmente relevante y apropiado a la edad del participante, que enseña sobre el sexo y las relaciones interpersonales a través del uso de información científicamente rigurosa, realista y sin prejuicios de valor (Unesco et al, 2010, pág. 2). 
De este aporte se desprende que la educación integral en sexualidad no es una simple materia, sino un enfoque de abordaje de manera científica y realista sobre el sexo y las relaciones que se entablan en la sociedad. Si se plantea que para que exista una educación en derechos humanos debe partirse del reconocimiento de la dignidad de la persona, es fundamental atender a la identidad cultural y etaria del participante, sería un atropello a la persona implementar un proceso de formación que pretenda aportar a su desarrollo integral desconociendo aspectos tan importantes de su personalidad.

Al considerar la relevancia cultural del enfoque integral de la educación en sexualidad, no debe darse lugar a relativismos o absolutismos que permitan crear o desarrollar los estereotipos y las prácticas que, desde una óptica de derechos humanos, se pretenden eliminar. Así, no puede alegarse la pertenencia a una determinada cultura para promover la subsistencia de prácticas que atentan contra la igualdad entre hombres y mujeres o la integridad física y mental de las personas.

Aunque en Guatemala no existe una definición legal de 'educación integral en sexualidad', existen algunos estándares internacionales que pueden servir como parámetro para definir sus alcances. Así, por ejemplo, el Comité de Derechos Económicos, Sociales y Culturales (1999) ha establecido que los Estados tienen la obligación de brindar educación integral a sus poblaciones, especialmente a las niñas, niños y adolescentes, cumpliendo los estándares de disponibilidad, accesibilidad y adaptabilidad que ha establecido en relación con el derecho a la educación y que este derecho

... desempeña un papel decisivo en la emancipación de la mujer, la protección de los niños contra la explotación laboral, el trabajo peligroso y la explotación sexual, la promoción de los derechos humanos y la democracia, la protección del medio ambiente y el control del crecimiento demográfico (párr.1).

El artículo 23 de la Convención Iberoamericana de Derechos de los Jóvenes (2005), reconoce el derecho a la educación sexual como fuente de desarrollo personal, afectividad y expresión comunicativa y, además, establece: 
La educación sexual se impartirá en todos los niveles educativos y fomentará una conducta responsable en el ejercicio de la sexualidad, orientada a su plena aceptación e identidad, así como, a la prevención de las enfermedades de transmisión sexual, el VIH/SIDA, los embarazos no deseados y el abuso o violencia sexual.

Finalmente, el artículo 6.b de la Convención Interamericana para prevenir, sancionar y erradicar la violencia contra la mujer -Convención de Belém do Pará- (1994) reconoce que el derecho de toda mujer a vivir libre de violencia incluye el derecho a "ser valorada y educada libre de patrones estereotipados de comportamiento y prácticas sociales y culturales basadas en conceptos de inferioridad o subordinación."

Fundamentar el derecho a la educación integral en sexualidad en la normativa nacional guatemalteca no es sencillo, pero tampoco imposible. Como se afirmó antes, existen preceptos constitucionales que reconocen el derecho a la educación con la finalidad de aportar al desarrollo integral de la persona, además, el derecho a acceder a una educación sexual está vinculado con el derecho de acceso a la información, reconocido en el artículo 35 de la ley fundamental.

El Acuerdo sobre Aspectos Socioeconómicos y Situación Agraria firmado por el Gobierno de la República de Guatemala y la Unidad Revolucionaria Nacional Guatemalteca (1996) como parte de los acuerdos de paz para terminar con el conflicto armado interno, contiene el compromiso de desarrollar una política estatal en materia educativa coherente con un programa nacional de salud integral para la mujer.

El decreto legislativo 27-2000 que contiene la Ley General para el Combate del Virus de Inmunodeficiencia Humana -VIH- y del Síndrome de Inmunodeficiencia Adquirida -SIDA- y de la promoción, protección y defensa de los derechos humanos ante el VIH/SIDA (2000), contempla que los ministerios de Salud Pública y Asistencia Social y de Educación, deben velar por la promoción y divulgación en materia de prevención, incluir contenidos curriculares en todos los niveles educativos y capacitar al cuerpo docente a nivel preventivo. 
La Ley de acceso universal y equitativo de servicios de planificación familiar y su integración en el Programa Nacional de Salud Reproductiva, decreto 87-2005, (2005), contempla que el Ministerio de Educación en coordinación con el Ministerio de Salud, debe garantizar que en el Currículum Nacional Base se incluya la educación sobre salud sexual y reproductiva y que se imparta, en los centros públicos y privados, durante la educación primaria, secundaria y en diversificado, abarcando contenidos como los derechos sexuales y reproductivos, la promoción del autocuidado de la salud, la sexualidad, el embarazo a temprana edad, el embarazo no deseado y la muerte materna.

Un aporte particularmente importante en esta materia lo proporciona la Ley de Desarrollo Social (Congreso de la República, 2001), en sus artículos del 27 al 31, regula lo relativo al derecho a la educación y a la educación en población. En esta ley se define la educación como un "proceso de formación integral del ser humano" que debe incluir aspectos de formación en derechos humanos y en población (Art. 27), que tiene como fin primordial el "desarrollo integral de las personas".

En cuanto a la educación en población, se establece que es una materia que debe ser incluida en todos los niveles y modalidades del sistema educativo nacional y que debe comprender al menos las temáticas relativas a "desarrollo, población, salud, familia, calidad de vida, ambiente, género, sexualidad humana, derechos humanos, multiculturalidad e interculturalidad, paternidad, maternidad responsable y salud reproductiva" (Art. 29).

Sobre los objetivos de esta materia, se contempla que se persigue "lograr una mejor calidad y expectativas de vida personal, familiar y social" implementando acciones educativas que permitan generar conciencia sobre la dignidad de la persona humana y formar actitudes positivas hacia "la paternidad y maternidad responsable, el sentido y el valor de la sexualidad" así como contribuir a la "educación integral de la población" para que las personas puedan decidir y asumir libre y responsablemente "sus acciones y roles en la vida familiar y social" (Art. 30). 
Finalmente, en cuanto a las orientaciones para integrar la educación en población a los planes y programas oficiales de estudio, la ley establece que la educación sexual debe estar orientada a desarrollar valores y principios éticos y morales que se sustenten en el "amor, comprensión, respeto y dignidad" y a fomentar un comportamiento personal que se base en la "concepción integral de la sexualidad humana en sus aspectos biológico, psicosocial y del desarrollo integral de la persona", por último, refiere que el contenido y las metodologías educativas tendrán que ser definidas por una comisión interseccional "en congruencia con el carácter científico y humanístico que establece la Constitución Política de la República" (Art. 31).

En este punto ya resulta necesario recordar que la educación integral en sexualidad desde un enfoque de derechos humanos no consiste únicamente en impartir una materia en un salón de clase, sino en crear un ambiente en el que toda la comunidad educativa participe de forma respetuosa y responsable en sus relaciones cotidianas, de índole personal o profesional, con respecto a los contenidos de la sexualidad de los demás. No sería un aporte real a la formación de los niños, niñas y adolescentes impartir una materia que desarrolle un contenido que es negado por la práctica de sus docentes y las demás personas que intervienen en su proceso educativo.

Así, por ejemplo, resulta fundamental evitar y reprimir los actos de discriminación o violencia de cualquier tipo, pero en particular aquellos que encuentran su fundamento en las relaciones de género, evitar la perpetuación de estereotipos a través de una división injustificada en las formas y contenidos de los aprendizajes, de los puestos de autoridad, de los puestos de servicio, etcétera.

El desarrollo legislativo de la obligación de contar con programas de formación que impliquen el reconocimiento de la sexualidad en el marco de la dignidad humana y el respeto y abordarla con un carácter científico y humanístico permite afirmar que existe una coincidencia entre los fines de la educación en sexualidad que se plantean en Guatemala y los propuestos por Unesco. En consecuencia, de acuerdo con Escobar de Corzantes (2010), "la educación sexual, integral y científica en Guatemala, es un derecho humano 
que cuenta con una sólida base legal que garantiza a todos los guatemaltecos el libre acceso a la información, para que vivan una sexualidad sana y responsable" (pág. 27).

\section{El derecho de los padres a elegir la educación que desean para sus hijos}

El artículo 73 de la Constitución guatemalteca establece que la familia "es fuente de la educación y los padres tienen derecho a escoger la que ha de impartirse a sus hijos menores." Este precepto, al igual que el referido a los fines de la educación, recoge los estándares desarrollados en varios instrumentos internacionales de derechos humanos. ${ }^{3}$

Una postura sobre este tema puede encontrarse en el voto razonado disidente de algunos diputados miembros de la Comisión Específica para la Revisión y Análisis de la Iniciativa de ley 3896, del Congreso de la República de Guatemala, quienes manifestaron:

La sexualidad debe ser propia del ámbito familiar, sin imposiciones de ningún tipo, ya que debe considerarse que vivimos en un país multiétnico, multicultural y plurilingüe donde cada cultura en base a sus propios valores y principios aborda la temática sexual desde su propia cosmovisión y en base a su propia pertinencia cultural. El artículo 1 de la Constitución Política de la República de Guatemala establece: como fin y deber del Estado la protección de la persona y de la familia. De esta cuenta debe respetarse y defenderse el derecho de los padres a educar a sus hijos

3 Declaración Universal de los Derechos Humanos. Artículo 26.3. Los padres tendrán derecho preferente a escoger el tipo de educación que habrá de darse a sus hijos.

Pacto Internacional de Derechos Económicos, Sociales y Culturales. Artículo 13.3. Los Estados partes en el presente Pacto se comprometen a respetar la libertad de los padres $\mathrm{y}$, en su caso, de los tutores legales, de escoger para sus hijos o pupilos escuelas distintas de las creadas por las autoridades públicas, siempre que aquéllas satisfagan las normas mínimas que el Estado prescriba o apruebe en materia de enseñanza, y de hacer que sus hijos o pupilos reciban la educación religiosa o moral que esté de acuerdo con sus propias convicciones.

Protocolo de San Salvador. Artículo 13.4. Conforme a la legislación interna de los Estados partes, los padres tendrán derecho a escoger el tipo de educación que habrá de darse a sus hijos, siempre que ella se adecue a los principios enunciados precedentemente. 
y escoger la educación para ellos (Comisión específica para la revisión y análisis a la iniciativa de ley 3896 "Ley Nacional de la Juventud”, 2016).

En efecto, mucho del contenido de la educación en sexualidad es impartido en casa. La comprensión de la sexualidad como una realidad que trasciende la genitalidad y las relaciones sexuales permite comprender que la forma en la que se tratan los padres o encargados, la forma en la que se reparten las obligaciones del hogar, la forma en la que se respeta o no la integridad física y psicológica de los miembros de la familia, son formas en las que se presentan y se inculcan actitudes vinculadas con el ejercicio de la sexualidad.

En cuanto a que los padres tengan derecho a escoger la educación que desean para sus hijos, existen algunas limitantes que deben ser tenidas en cuenta. La redacción del artículo constitucional guatemalteco no presenta ninguna restricción, sin embargo, tampoco existe una afirmación que permita considerar que este es un derecho absoluto. En algunos instrumentos internacionales es posible encontrar una definición más limitada. En el Pacto Internacional de Derechos Económicos Sociales y Culturales, se establece que este derecho se refiere únicamente a la "educación religiosa o moral" y, a nivel regional, en el Protocolo de San Salvador, se refiere que el derecho de los padres está limitado a que la educación se "adecue a los principios enunciados"4; así, al recordar la definición de educación integral en sexualidad y los contenidos que abarca, referidos anteriormente, resulta difícil encuadrarlos dentro de los espacios de decisión que los citados tratados reconocen a los padres de familia.

Ante la falta de definición legal, la Corte de Constitucionalidad ha establecido algunos límites a este derecho. En la sentencia dictada dentro del expediente 2026-2010, el tribunal constitucional consideró que el derecho de los padres de optar por una educación a distancia, sólo se justifica cuando no existe accesibilidad por cuestiones de distancia a un centro educativo que permita gozar del derecho de educación a sus hijos. En esa misma sentencia, la Corte tomó como base de su razonamiento la Observación General número 1 del Comité de los Derechos del Niño, la que citó textualmente, y que dispone:

$4 \quad$ Para un listado de los principios, ver nota al pie 2. 
La educación a que tiene derecho todo niño es aquella que se concibe para prepararlo para la vida cotidiana, fortalecer su capacidad de disfrutar de todos los derechos humanos y fomentar una cultura en la que prevalezcan unos valores de derechos humanos adecuados. El objetivo es habilitar al niño desarrollando sus aptitudes, su aprendizaje y otras capacidades, su dignidad humana, autoestima y confianza en sí mismo. En este contexto la "educación es más que una escolarización oficial y engloba un amplio espectro de experiencias vitales y procesos de aprendizaje que permiten al niño, ya sea de manera individual o colectiva, desarrollar su personalidad, dotes y aptitudes y llevar una vida plena y satisfactoria en el seno de la sociedad" (Corte de Constitucionalidad, 2010, pág. 5).

De acuerdo con este criterio jurisprudencial, el primer límite al derecho de los padres a elegir la educación que desean para sus hijos es, justamente, el derecho a la educación de sus hijos, mismo que contiene, por lo menos, todo lo expresado por el Comité de Derechos del Niño.

En la sentencia emitida dentro de los expedientes acumulados 1202-2006, 1288-2006 y 1451-2007, la Corte provee otro criterio que define un nuevo límite para el derecho de los padres. De acuerdo con el tribunal:

...el derecho de los padres de escoger la educación que ha de impartirse a los hijos menores está reconocido en función de la educación de tipo religioso, filosófico y moral, no para oponerse a las enseñanzas en estas materias sino para que las mismas se hagan según las convicciones de los padres. Así, el derecho de los padres de escoger la educación que ha de impartirse a los hijos no significa que éstos puedan oponerse a las materias que involucran cuestiones de la moral o de la religión -como puede ser la educación sexual en algunos aspectos-, sino a escoger el tipo -conservador o liberal, como bien se le quiera llamar- en las materias que se le impartan. Cabe apuntar también que si el derecho de los padres de escoger la educación que ha de darse a los hijos, se ejerce en los ámbitos apuntados, queda excluido de este derecho la posibilidad de escogencia, la educación de las ciencias, las letras o la historia. 
Por ello, el derecho de los padres de escoger la educación que ha de impartirse a los hijos menores, no apareja que el Estado esté imposibilitado de crear e imponer ciertos contenidos en los programas de estudio. (Corte de Constitucionalidad, 2008, pág. 37).

En este caso se discutía directamente la inclusión de algunos contenidos vinculados con la educación en sexualidad a los estudiantes del sistema de educación nacional, por lo que resulta relevante que la Corte impone límites más claros al derecho de los padres, reduciéndolo a materias que tienen que ver con la religión, filosofía y moral y todavía más importante, que excluye a la educación sexual de esas materias, podría colegirse que el tribunal la incluye dentro de las relativas a las ciencias, en las que veda la posibilidad de intervención parental.

Otro límite importante que se marca en esta sentencia es el relativo a la forma en la que se puede ejercer este derecho y es que los padres no tienen potestad para decidir sobre el contenido de los cursos (y tampoco sobre la forma de impartirlos si se considera que existe un reconocimiento constitucional a la libertad de cátedra), su derecho les permite únicamente elegir un centro educativo en el que los contenidos sobre estos temas se impartan según sus creencias 5 .

Finalmente, la Corte también reconoce la potestad del Estado de desarrollar contenidos obligatorios, mismos que no pueden ser objetados por los padres de familia desde el argumento del derecho de elegir la educación que desean para sus hijos.

En relación con las disposiciones que tome el Ministerio de Educación, la Corte estableció que deben atender al interés superior del niño y deben garantizar "el derecho a la educación integral y eficaz de todos los niños, niñas y adolescentes" (Corte de Constitucionalidad, 2016, pág. 10). De lo que se desprende que tampoco el Estado está facultado para tomar decisiones que pudieran disminuir la integralidad de la educación de los estudiantes.

$5 \quad$ A partir de este razonamiento la Corte de Constitucionalidad podría desarrollar el derecho de los padres a conocer los contenidos ideológicos de los programas de estudio sobre religión, filosofía y moral que se imparten en los centros educativos, para poder tomar una decisión informada sobre la opción que pudieran elegir para sus hijos. 
En síntesis, la Corte de Constitucionalidad ha establecido hasta el momento límites al derecho de los padres a elegir la educación que desean para sus hijos en función del derecho a la educación que poseen los estudiantes, asumiendo una postura de protección de este último frente a la importancia que reviste proveer de una formación integral a los niños, niñas y adolescentes para procurarles un desarrollo de la personalidad capaz de permitirles optar por un proyecto de vida que les permita alcanzar una vida digna en una sociedad plural y democrática. Atendiendo a que se trata de niños y niñas, la Corte ha establecido que, ante cualquier decisión de las autoridades educativas, debe tomarse en consideración el principio del interés superior del niño, con lo que existe una limitación también para el poder público respecto a las políticas y contenidos educativos.

\section{La libertad de religión}

El artículo 36 de la Constitución guatemalteca reconoce la libertad de religión. De acuerdo con la norma, el derecho comprende la práctica en público y privado a través de la enseñanza, el culto y la observancia. Esta libertad también está reconocida en tratados internacionales en materia de derechos humanos ${ }^{6}$.

$6 \quad$ Pacto Internacional de Derechos Civiles y Políticos. Artículo 18.

1. Toda persona tiene derecho a la libertad de pensamiento, de conciencia y de religión; este derecho incluye la libertad de tener o de adoptar la religión o las creencias de su elección, así como la libertad de manifestar su religión o sus creencias, individual o colectivamente, tanto en público como en privado, mediante el culto, la celebración de los ritos, las prácticas y la enseñanza.

2. Nadie será objeto de medidas coercitivas que puedan menoscabar su libertad de tener o de adoptar la religión o las creencias de su elección.

3. La libertad de manifestar la propia religión o las propias creencias estará sujeta únicamente a las limitaciones prescritas por la ley que sean necesarias para proteger la seguridad, el orden, la salud o la moral públicos, o los derechos y libertades fundamentales de los demás.

4. Los Estados Partes en el presente Pacto se comprometen a respetar la libertad de los padres y, en su caso, de los tutores legales, para garantizar que los hijos reciban la educación religiosa y moral que esté de acuerdo con sus propias convicciones.

Convención Americana sobre Derechos Humanos. Artículo 12. Libertad de Conciencia y de Religión.

1. Toda persona tiene derecho a la libertad de conciencia y de religión. Este derecho implica la libertad de conservar su religión o sus creencias, o de cambiar de religión o de creencias, así como la libertad de profesar y divulgar su religión o sus creencias, individual 
Huaco Palomino (2014) define esta libertado como:

La libertad de profesar o no profesar una religión, entendida ésta como la relación del hombre con lo divino (no necesariamente con un dios personal, sino con lo divino que es una relación con la trascendencia) de la cual se desprenden determinadas convicciones éticas, opiniones, creencias y observancias religiosas las cuales se exteriorizan positivamente a través de la libre manifestación individual o colectiva, pública o privada, a través de diversas concreciones particulares (pág. 295).

De la definición citada se desprende que forma parte de la libertad de religión el hecho de tener o no tener una en particular y si se posee, de desarrollarla vinculada con una deidad o no. Resulta importante tener esto presente porque a la luz de estos criterios se va perfilando que el bien jurídico que se tutela no es 'una' religión o 'la' religión, sino la libertad de la persona ejercida en el ámbito religioso.

La Corte de Constitucionalidad se ha pronunciado sobre el contenido de esta libertad, afirmando que la Constitución garantiza el libre ejercicio de todas las religiones, de donde se desprende la laicidad del Estado, y una libertad, a la que podría denominarse orgánica, de las iglesias que,

... atañe a concretamente a distintos aspectos que incumben al ejercicio y práctica de la creencia o religión de que se trata, entre los que destacan, necesariamente, los actos propios al culto, la estructura jerárquica de la organización eclesiástica y la relación de la iglesia con sus creyentes o fieles (Corte de Constitucionalidad, 2015).

o colectivamente, tanto en público como en privado.

2. Nadie puede ser objeto de medidas restrictivas que puedan menoscabar la libertad de conservar su religión o sus creencias o de cambiar de religión o de creencias.

3. La libertad de manifestar la propia religión y las propias creencias está sujeta únicamente a las limitaciones prescritas por la ley y que sean necesarias para proteger la seguridad, el orden, la salud o la moral públicos o los derechos o libertades de los demás.

4. Los padres, y en su caso los tutores, tienen derecho a que sus hijos o pupilos reciban la educación religiosa y moral que esté de acuerdo con sus propias convicciones. 
En cuanto a las implicaciones que podría tener la libertad religiosa respecto a la educación integral en sexualidad y el derecho de los padres a elegir la educación que desean para sus hijos, ya fue expuesto arriba que la Corte consideró que aquella se encontraba fuera de las materias que podrían considerarse afectas al derecho que asiste a los padres y tutores. Además, encuentra sustento normativo y jurisprudencial la potestad del Estado para determinar los contenidos mínimos y obligatorios de los planes de estudio, los cuales debe desarrollar sin favorecer un pensamiento religioso en particular, sino el interés superior del niño en una sociedad democrática y plural.

La libertad religiosa tiene dos dimensiones tutelables; una positiva que se caracteriza por la libertad de la persona para tener o manifestar alguna $o$ ninguna filiación religiosa y una negativa, que impone al Estado el deber de abstención para llevar a cabo acciones a favor o en contra de cualquier religión. Sobre esta última, Dworkin (2014) afirma:

Se entiende que todas estas disposiciones tienen consecuencias políticas dramáticas. Prohíben claramente que el gobierno penalice la afiliación a cualquier religión tradicional o a ninguna de ellas. Suelen entenderse, aunque no de manera universal, también como una prohibición para que el gobierno declare a cualquier religión una religión oficial de Estado o para que apoye a una religión o a todas mediante subsidios o cualquier otro privilegio especial, o para que permita restricciones legales de cualquier tipo que asuman que una religión se prefiere sobre otras o que esa religión es preferible a ninguna (pág. 69).

La dimensión positiva de la libertad religiosa contiene la libertad de manifestarla a través de la enseñanza, la práctica, el culto o los ritos y el derecho a intentar convencer a los demás. Para esto último, los miembros de una religión pueden tener dos comportamientos: "existe una radical diferencia entre el comportamiento religioso testimonial y el 'proselitismo que no es respetable, siendo este aquel que consiste en métodos inmorales, engañosos o indignos para intentar convencer a una persona a determinada convicción religiosa” (Cervantes, 2009, pág. 128). De acuerdo con este criterio, podría ser considerado como proselitismo religioso inadecuado la imposición de una doctrina religiosa como parámetro de la sexualidad humana de forma universal en el sistema educativo. 
No existe prohibición para que exista una orientación religiosa en relación con la sexualidad, de hecho, como ya se afirmó antes, existe una relación entre ambas dimensiones de la realidad humana, sin embargo, el derecho a la educación que les asiste a los niños, niñas y adolescentes, exige que además de la valoración de índole religiosa se presenten otras, desde otras posturas y que sea el estudiante el que, en ejercicio de su libertad y capacidad de discernimiento, determine cuál es la postura que va a adoptar para desarrollar su propio plan de vida. Al respecto, la Corte de Constitucionalidad manifestó:

Poner en conocimiento del estudiante, no necesariamente significa orientarle en alguna postura definida por el Estado ni del propio establecimiento, precisamente porque se le educa para crearle una conciencia crítica que no podría desarrollar si se le niega el acceso a la educación en cualquier materia, dentro de la que puede incluirse el autocuidado de la salud y la sexualidad y está en su libertad de enseñanza, manifestarle su postura y lo que, a su juicio, es el deber ser en esa materia, sin embargo, ha de respetar la posición del propio alumno en el tema, porque también está en el ámbito de su libertad, la cual no podrá escoger si vive en la ignorancia (Corte de Constitucionalidad, 2008, pág. 42). 


\section{CONCLUSIÓN}

Atendiendo a lo desarrollado por Robert Alexy (2002):

... la ponderación se puede dividir en tres pasos. En el primer paso es preciso definir el grado de la no satisfacción o de afectación de uno de los principios. Luego, en un segundo paso, se define la importancia de la satisfacción del principio que juega en sentido contrario. Finalmente, en un tercer paso, debe definirse si la importancia de la satisfacción del principio contrario justifica la afectación o la no satisfacción del otro (pág. 32).

El derecho de los padres a elegir la educación que desean para sus hijos ha sido limitado en varios sentidos: primero, en relación con la materia, estableciendo que únicamente es aplicable a aquellos casos en los que la educación se refiere a temas vinculados con la religión y la moral; segundo, en relación con los fines del derecho a la educación; y, tercero, en relación con el derecho a la educación en sí mismo y sus beneficiarios, los alumnos.

Fue la Corte de Constitucionalidad la que determinó que la educación en sexualidad no forma parte de los contenidos relativos a la religión y la moral, por lo que la excluyó del espacio en el que los padres pueden optar por la educación que desean para sus hijos, reconociendo, además, la potestad del Estado para crear e imponer algunos contenidos a los programas de estudio siempre que se atienda al principio del interés superior del niño.

Si se entiende el derecho de los padres como una especie de poder de veto respecto a los contenidos de los cursos y materias, entonces puede afirmarse que ha sido afectado totalmente respecto a la educación en sexualidad, porque ha sido excluida del espectro protector de este derecho. Sin embargo, si se entiende el derecho de los padres como una función preventiva que implica la investigación y el análisis de los programas de estudio de los establecimientos educativos y su identificación ideológica para tomar una decisión informada sobre el lugar en el que sus hijos recibirán educación, entonces no hay una afectación total, sino relativa, porque existe una adhesión de los padres a la forma y modo que les fue propuesta por la institución para educar a los estudiantes. 
El derecho a la educación está relacionado con el desarrollo integral de la persona y tiene una influencia muy significativa en la definición de un proyecto de vida que le permita a las personas participar en una sociedad democrática y plural. La sexualidad ha sido entendida como una de las dimensiones de la personalidad que se manifiesta en todos los aspectos de la vida, por lo que contar con una educación al respecto se puede considerar como un elemento fundamental para el desarrollo de la identidad y para prevenir actos que impliquen violaciones a la indemnidad y a la integridad de las personas.

En Guatemala la educación en sexualidad ha sido incluida en el ámbito de la educación en desarrollo, lo que implica una relación directa entre esta característica de la individualidad personal con uno de los objetivos de índole social más importantes del país. De esa forma, se demuestra que no existen elementos para considerar que vivencia de la sexualidad pueda ser considerada como un asunto que tenga que ver únicamente con el individuo, sin afectar la forma en la que se va desenvolviendo la sociedad. Atendiendo al principio de que el bien común prevalece sobre el particular y a que la creación de ambientes educativos que permitan una educación integral en el respeto y la dignidad de todas las personas en relación con la sexualidad no solo no atenta, sino que garantiza el interés superior del niño, resulta justificable que el Estado intervenga para garantizar que los niños, niñas y adolescentes accedan a una educación integral, científica y humanista sobre la sexualidad humana. 


\section{BIBLIOGRAFÍA}

Alexy, R. (2002). Epílogo a la Teoría de los Derechos Fundamentales. Revista Española de Derecho Constitucional, 13-64.

Arango de Montis, I. (2008). Historia breve de la sexología clínica en occidente. En I. Arango de Montis (Ed.), Sexualidad humana (págs. 1-10). México: Editorial Manual Moderno.

Asamblea General. (2012). Declaración de las Naciones Unidas sobre educación y formación en materia de derechos humanos. A/RES/66/137. Naciones Unidas.

Cervantes, L. F. (2009). Los principios generales sobre la libertad religiosa en la jurisprudencia de los sistemas europeo, interamericano y costarricense de protección de los derechos humanos. Senderos: revista de ciencias religiosas y pastorales , 123-143.

Comisión específica para la revisión y análisis a la iniciativa de ley 3896 "Ley Nacional de la Juventud”. (2016). Dictamen a la iniciativa de ley número 3896 que dispone aprobar la "Ley Nacional de la Juventud". Guatemala: Congreso de la República de Guatemala.

Comisión Interamericana de Derechos Humanos. (6 de marzo de 1998). Informe No. 28/98 caso 11,625. María Eugenia Morales de Sierra contra Guatemala .

Comité de Derechos Económicos, Sociales y Culturales. (1999). Observación general No. 13. El derecho a la educación (artículo 13).

Comité de los Derechos del Niño. (17 de abril de 2001). Observación General No. 1. Párrafo 1 del artículo 29: Propósitos de la Educación. CRC/GC/2001/1.

Congreso de la República de Guatemala. (julio de 2000). Decreto 27-2000. Ley gene3ral para el combate del Virus de Inmunodeficiencia Humana VIH y del Síndrome de Inmunodeficiencia Adquirida SIDA y de la promoción, protección y defensa de los Derechos Humanos ante el VIH/SIDA. Guatemala.

(19 de noviembre de 1998). Decreto número 80-98. Reformas al decreto ley número 106 del Jefe de Gobierno, Código Civil. Guatemala: Tipografía Nacional.

(26 de septiembre de 2001). Decreto 42-2001. Ley de desarrollo social. Guatemala.

(16 de noviembre de 2005). Decreto 87-2005. Ley de acceso universal y equitativo de servicios de planificación familiar y su integración en el programa nacional de salud reproductiva. Guatemala.

Convención Americana sobre Derechos Humanos. (1969).

Córdoba García, D. (2007). Teoría Queer: Reflexiones sobre sexo, sexualidd e identidad. Hacia una politización de la sexualidad. En D. Córdoba, J. Sáez, \& P. Vidarte (Edits.), Teoría Queer. Políticas bolleras, maricas, trans, mestizas (págs. 21-66). Madrid: Egales, S.L. 
Corte de Constitucionalidad - Instituto de Justicia Constitucional. (2019). Constitución Política de la República de Guatemala con notas de jurisprudencia de la Corte de Constitucionalidad y de la Corte Interamericana de Derechos Humanos. (C. d.-I. Constitucional, Ed.) Guatemala: Cimgra.

(20 de septiembre de 2010). Sentencia de Apelación de Sentencia de Amparo dentro del expediente 2026-2010. Guatemala, Guatemala, Guatemala.

(15 de enero de 2015). Sentencia de Apelación de sentencia de amparo dentro del expediente 2189-2013. Guatemala.

(24 de junio de 1993). Sentencia de inconstitucionalidad directa dentro del expediente 84-92. Guatemala.

(8 de enero de 2008). Sentencia de Inconstitucionalidad General dentro de los expedientes acumulados 1202-2006, 1288-2006 y 1451-2007. Guatemala, Guatemala, Guatemala.

(8 de septiembre de 2016). Sentencia de Inconstitucionalidad General dentro del expediente 4390-2015. Guatemala, Guatemala, Guatemala.

Dworkin, R. (2014). Religión sin dios. Buenos Aires: Fondo de Cultura Económica de Argentina.

Escobar de Corzantes, M. (2010). Educación integral de la sexualidad en el sistema educativo guatemalteco: un estado del arte. Guatemala: Ministerio de Educación.

Escuela bíblica y arqueológica francesa de Jerusalén. (2007). Deuteronomio. En La Biblia de Jerusalén. Bilbao: Desclée de Brouwer.

Gobierno de la República de Guatemala y Unidad Revolucionaria Nacional Guatemalteca. (6 de mayo de 1996). Acuerdo sobre aspectos socioeconómicos y situación agraria. México.

Huaco Palomio, M. (2014). Artículo 12. Libertad de Conciencia y de Religión. En C. Steiner, \& P. Uribe (Edits.), Convención Americana sobre Derechos Humanos. Comentario (págs. 289-319). Bogotá: Editorial Themis.

Opinión Consultiva 24/17. Identidad de género e igualdad y no discriminación a parejas del mismo sexo. Obligaciones estatal3es en relación con el cambio de nombre, la identidad de género, y los derechos derivados d eun vínculo entre parejas del mismo sexo, Serie A No. 24 (Corte Interamericana de Derechos Humanos 24 de noviembre de 2017).

Organización de Estados Americanos. (9 de junio de 1994). Convención interamericana para prevenir, sancionar y erradicar la violencia contra la mujer. Belem do Para.

Organización Iberoamericana de Juventud. (11 de octubre de 2005). Convención Iberoamericana de Derechos de los Jóvenes. Badajoz. 
Relator especial de las Naciones Unidas sobre el derecho a la educación. (23 de julio de 2010). Informe del relator especial de las Naciones Unidas sobre el derecho a la educación A/65/162. Organización de las Naciones Unidas.

Unesco. (2014). Educación integral en sexualidad: conceptos, enfoques y competencias. Santiago: Unesco.

et al. (2010). Orientaciones Técnicas Internacionales sobre Educación en Sexualidad (Vol. I Justificación de la educación en sexualidad). Unesco.

(2010). Orientaciones Técnicas Internacionales sobre Educación en Sexualidad (Vol. I Justificación de la educación en sexualidad). Unesco.

(2003). Unesco y educación para los derechos humanos. Paris: Unesco.

Vera-Gamboa, L. (1998). Historia de la sexualidad. Revista Biomédica , 116-121.

Wagner Mota, K. P. (2013). El derecho internacional de los derechos humanos y las obligaciones de los Estados. Guatemala: Instituto de Investigaciones Jurídicas de la Universidad Rafael Landívar. 